\title{
Sistem Advice Planing Online Dengan Framework Codeigniter Berbasis Web Bootstrap (Studi Kasus: Kabupaten Probolinggo)
}

\author{
Moh. Ainol Yaqin ${ }^{\left.1^{*}\right)}$, Abdullah Al Anis ${ }^{2}$ \\ ${ }^{1,2}$ Jurusan Informatika, Fakultas Teknik, Universitas Nurul Jadid, Paiton Probolinggo \\ ${ }^{1,2}$ Jln. KH. Zaini Mun'im Karangayar Paiton, Probolinggo, Indonesia \\ email: 1ainolyaqin09@mail.com, 2abdullah81alanisfauzi@mail.com
}

Received: 20 Maret 2018; Revised: 10 Mei 2018; Accepted: 13 Mei 2018

Copyright @2018 Politeknik Harapan Bersama Tegal. All rights reserved

\begin{abstract}
Information system in the form of Integrated Advice Planning by using CodeIgniter Framework and based on Framework Bootstrap one of system which gives responsive form. The system is a service as one of solution for eGovernment. Advice Planning service is the optimization of public services in the licensing sector and the optimization of agency management. The licensing service is in the form of design consultation and the location of the building in accordance with the Spatial and Regional Plan within a Local Government. Licensing process that must be fulfilled by prospective investors either individually or on behalf of the company and supporting infrastructure around the investment location. The services provided by the Information System have provided Advice Planning application submission online. The system is expected to provide convenience for the community in the region and create a friendly, the comfortable, the transparent and cheap of interaction between the government and the community
\end{abstract}

Abstrak - Sistem informasi berupa Advice Planning Terpadu dengan menggunakan Framework CodeIgniter dan berbasis Framework Bootstrap, salah satu sistem yang front end yang responsif. Sistem tersebut merupakan layanan jasa sebagai salah satu solusi e-goverment. Pelayanan Advice Planning merupakan optimalisasi pelayanan publik dalam sektor perijinan dan optimalisasi manajemen instansi. Pelayanan perijinan berwujud konsultasi desain dan letak bangunan yang sesuai dengan Rencana Tata Ruang dan Wilayah di dalam suatu Pemerintah Daerah. Proses perizinan yang harus dipenuhi oleh calon investor baik secara individu atau atas nama perusahaan serta infrastruktur pendukung yang ada di sekitar lokasi investasi. Layanan jasa dari Sistem Informasi yang telah diibuat menyediakan pengajuan permohonan Advice Planning secara online. Dengan adanya sistem tersebut diharapkan akan memberikan kemudahan bagi masyarakat pada daerahnya serta menciptakan interaksi yang ramah, nyaman, transparan dan murah antara pemerintah dan masyarakat.

Kata Kunci: E-goverment, sistem informasi, Advice Planning, framework CI, Bootstrap

\footnotetext{
*) Corresponding author: Moh. Ainol Yaqin

Email: ainolyaqin09@mail.com
}

\section{PENDAHULUAN}

Perkembangan teknologi di era modern saat ini mengalamai kemajuan yang sangat pesat. Perkembangan tersebut mencakup semua bidang kehidupan salah satunya adalah dengan adanya teknologi informasi [1]. Penerapan Teknologi Informasi [2] adalah suatu proses yang digunakan untuk memberikan kemudahan bagi pemerintahan, pemerintah yang baik ialah pemerintah yang memberikan pelayanan cepat, tepat, efiesien dan efektif. Berkembangnya teknologi seiring dengan perkembangan website, dimana semua kalangan seperti instansi pemerintah, swasta, perusahaan maupun perguruan tinggi menggunakan website untuk proses pengolahan data maupun memberikan informasi [3].

Pemanfaatan teknologi informasi yang berbasis website ini juga mendukung konsep dasar dari e-Goverment untuk menciptakan interaksi yang searah antara ramah, nyaman, transparan dan murah anatara pemerintah dengan masyarakat ( $G 2 C$ - Government to Citizens), pemerintah dengan perusahaan yang berbasis bisnis $(G 2 B$ - Government to Business Enterprises) dan hubungan antar pemerintah (G2G-inter-agency relationship). Salah satunya yaitu Advice Planning yang merupakan pelayanan publik dalam sektor perijinan dan optimalisasi manajemen instansi pelayanan perijinan yang berwujud konsultasi desain dan letak bangunan yang sesuai dengan Planing Tata Ruang, tempat dan Wilayah di dalam suatu Pemerintah Daerah.

Advice Planning adalah syarat yang harus dipenuhi untuk memperoleh IBM atau Izin mendirikan Bangunan. Permohonan Advice Planning ini dapat dilakukan atas nama perorangan atau dapat pula atas nama perusahaan [4]. Dalam pengajuan Advice Planning terdapat banyak persyaratan berkas yang harus dipenuhi oleh seorang pemohon yang diajukan kepada Dinas Tata Kota atau Kantor Pelayanan Perijinan Terpadu pada daerahnya. Proses perijinan yang dilakukan secara manual harus mendatangi kantor Dinas Tata Kota untuk mengambil formulir permohonan dan persyaratan berkas yang harus dipenuhi. Kemudian setalah melengkapi permohonan dapat menunggu beberapa hari hingga hasil Advice Planning tersebut telah diterbitkan oleh dinas yang bersangkutan. Maka dari itu, 
untuk meningkatkan kulitas pelayanan terhadap publik dan meningkatkan partisipasi secara aktif dalam pemberian informasi bagi masyarakat maka diperlukanlah perbaikanperbaikan dalam hal pelayanan kepada masyarakat diantaranya dengan semaksimal mungkin memanfaatkan keunggulan teknologi informasi dengan membuat Sistem Advice Planning Online Terpadu memggunkan CI dan Bootstrap yang diharapkan akan membawa manfaat sehingga pelayanan menjadi lebih mudah dan mempersingkat waktu. Pemohon akan mendapatkan hasil Advice Planning secara online dan dapat langsung diunduh serta dicetak pada akun masing-masing. Layanan ini diberikan gratis kepada masyarakat. Dengan adanya sistem tersebut dapat memberikan kemudahan dalam pelakukan pendirian bangunaan secara online dan cepat pelayanannya.

\section{PENELITIAN YANG TERKAIT}

Santoso, Budi dkk [5] pembahasan tentang Sistem Informasi Geografis Penataan Ruang dan Bagunana Berbasis Web di Kantor Dinas Cipta Karya Tata Runag dan Perumahan Kota Pontianak, berawal dari Fungsi dari Dinas Cipta Karya adalah pengaturan Tata Ruang dan perumahan Kota Pontianak yang memberikan hak penuh kepada masyarakat dalam memberikan advis planning di bidang perencanaan mendirikan bagunan di kota Pontianaka supaya dapat menyesuaikan dengan tata ruang di kota tersebut. Namun, dalam penyampaian advis planing yang akan mengajukan masih bersifat tidak efesien karena masyarakat harus mendatangi kantor tersebut dan menemui petugas front office. Hal ini, masih terbatas waktu dan tempat, sehingga dapat mengganggu aktifitas masyarakat yang notabene adalah karyawan atau guru. Apalagi ditambah masyarakat harus menjelaskan secara rinci lokasi dengan menggunakan peta analog dalam bentuklembaran kertas dengan skala 1:70000. Pencarian data tempat bangunan masih manual dengan menggunakan sumber seadaanya. Dari permasalahan tersebut maka adanya Sistem Informasi Geografis dengan lebih efisien waktu dan informasi, tanpa terbatasannya ruang dan waktu. Pada sistem tersebut menggunakan metode Water Fall (siklus air terjun) artinya akan membahas yang lainnya jika permasalahan sebelumnya terselesaikan.

Perbandingan antara penelitian rujukan pertama dan penelitian yang akan dilakukan adalah dalam segi kecanggihan teknologi yang digunakan, dimana penelitian masih belum menggunakan web yang responsive yang mana comfortable dengan dunia mobiling atau HP android yang secara lagi booming dan banyak digunakan oleh banyakan masyarakat luas, dalam segi keamanan menggunakan framework lebih memiliki sistem keamanan yang kuat dari pada Native PHP. [6]. Dari itu, penelitian yang akan dilakukan saat akan lebih berguna dari tingkat keamanan, kebutuhan dalam menggunakan handphone dan menyesuaikan dengan kebutuhan masyarakat Probolinggo.

Efektivitas Advice Planning Dalam Pelayanan Izin Mendirikan Bangunan di Kota Pematangsiantar adalah jurnal penelitian kedua oleh Sembiring, M.S.A (2015). Pada penelitian kedua adalah salah tentang proses pembangunan tata letak Perijinan mendirikan Bagunanan di Kota Pematangsianta, agar terasa lengkap dari proses IT-nya dan proses manual yang berupa jurnal tentang Advis Planning. Hasil dari penelitian di atas adalah Berdasarkan penelitian yang dilakukan dan hasil wawancara yang dilakukan dapat dinyatakan bahwa Advice Planning dalam Pelayanan Izin Mendirikan Bangunan di Kota Pematangsiantar belum efektif. Hal tersebut ditunjukkan oleh masih sering dijumpai adamya bangunan yang didirikan melanggar peraturan yang berlaku. Berdasarkan bukti yang terlihat selama penelitian koordinasi antar aparatur pemerintah juga sangat tidak baik, mereka menjadikan suatu

pekerjaan yang harusnya dikerjakan bersama atau saling koordinasi malah dijadikan persaingan antar kantor dinas. Dibuktikan juga dalam wawancara langsung tentang Advice Planning antara Dinas Perizinan dan Dinas Tata Kota saling memojokkan [7]. Dari aspek Hukum Kenegaraan dalam bidang perizinan pendirian bangunan pada Advice Planning. Penelitian ini akan menggabungkan dari aspek TI dan izin mendirikan bangunan, dengan cara bentuk kerjasama dengan pemerintahaan, khususnya Kabupaten Probolinggo, Propinsi Jawa Timur. Penelitian ini adalah solusi dalam memberikan kemudahan baik bagi pengaju ataupun bagi pemerintah setempat.

Penelitian rujukan ketiga adalah Implementasi Penerbitan Ijin Mendirikan Bangunan Dalam Prespektif Azas-Azas Umum Pemerintahan yang Baik Di Kabupaten Sukamara oleh, dalam penelitian tersebut membahas implementasi fungsi pelayanan pemerintah kabupaten dalam memberikan ijin mendirikan bagunanan dan menangani kendala menuju pada pelayanan yang baik sehingga sesuai dengan azaz-azaz umum dalam memberikan perijinan mendirikan bagunan secara baik dan benar [8]. Sama dengan penelitian sebelumnya tidak memberikan kemudahan dalam masyarakat dalam mendirikan bagunan karena masih tidak berbasis teknologi (TI). Hanya sekedar mengatur tentang proses berjalanya suatu administrasi pendirian secara manual.

Muhammad Ridha Albaar dan Rosdiani Achmad [9] peneliti tentang analisis sistem informasi pelayanan izin mendirikan bangunan menggunakan pendekatan Framework ITPOSMO (Studi Kasus Dinas Tata Kota dan Pertamanan Kota Ternate). Dalam penyajian analisis Sistem informasi pelayanan Izin pendirian Bangunan secara besaran menggunakan framework ITPOSMO adalah Konsep kesenjangan pada program yang dijalankan oleh $e$-goverment di negara berkembang mengenai informasi, Teknologi, proses, objektif dan nilai [10]. Metode tersebut digunakan untuk tidak adanya kegagalan atau kesenjangan program pada e-goverment. Ketidak tepatan yang sering terjadi dalam proses izin mendirikan bangunan terletak pada ruang lingkup pekerjaan, perancangan penjadwalan dan estimasi biaya, maka dari itu sistem tersebut akan sangat membantu agar lebih tepat sasaran, tepat hitungan dan pekerjaan tidak ada yang dilewati. Sistem ini bertujuan memperbaik pelayanan terdapat masyarakat, sistem informasi ini berbasis desktop.

Penelitan rujukan dengan penelitian yang akan dilakukan memiliki gap atau perbedaan yang menonjol, tampak dari teknologi yang digunakan sesuai dengan kebutuhan pada zaman sekarang. Pertama mengunakan web codeigniter, memiliki keamana yang baik karena berbasis framework, kedua memanfaatkan fasilitas dari bootstrap, front end yang responsif, sehingga bentuk dapat menyesuaian dengan flatform yang digunakan seperti handphoe, iPad dan tablet. Dari beberapa gap yang ada maka sangat perlu membangun sistem informasi tersebut. 


\section{METODE PENELITIAN}

Kerangka Pemikiran dalam metodologi penelitian yang digunakan dalam perancangan Sistem Informasi Advice Planning studi kasus Kabupaten Probolinggo adalah sebagai berikut:

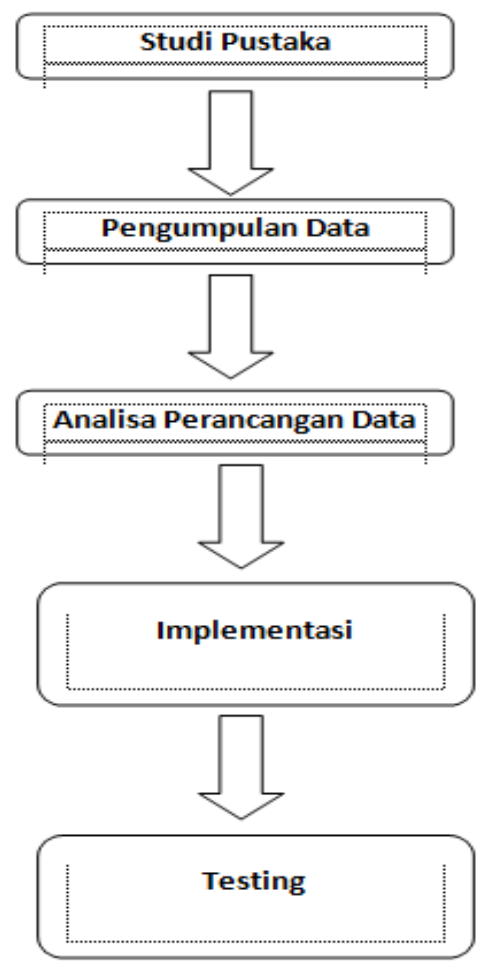

Gbr. 1 Kerangka Pemikiran

\section{A. Studi Pustaka}

Metode studi pustaka dilakukan dengan mencari sumber dan alternatif yang dapat digunakan sebagai bahan analisis dan perancangan sistem. Studi pustaka dilakukan dengan mencari sumber dari media online [11] dan buku literatur yang sesuai dengan kebutuhan pembahasan.

\section{B. Pengumpulan Data}

Metode pengumpulan data dilakukan dengan mempelajari proposal Advice Planning yang sebelumnya telah dibuat oleh pihak Pemerintahan Kabupaten Probolinggo. Selain itu, mencari data via telepon ke Dinas Probolinggi untuk mengetahui lebih akurat mengenai sistem Advice Planning yang telah ada (web Advice Planning milik Kabupaten Probilinggo) untuk dijadikan bahan pertimbangan serta contoh sistem informasi Advice Planning yang telah ada dan masih berjalan.

\section{Analisa Perancangan Sistem}

Metode analisa perancangan sistem merupakan tahap yang dilakukan untuk menganalisa kebutuhan sistem yang akan dibangun dengan menentukan scope permasalahan [12]. Proses analisa dan perancangan sistem terdiri dari pembuatan model use case, activity diagram, sequence diagram, ER diagram, serta class diagram. Selain itu, pada tahap ini juga dibuat mock up dari sistem Advice Planning yang akan dibangun agar lebih detail

\section{Implementasi}

Setelah perancangan selesai dibuat, maka yang akan dilakukan membangun Sistem Advice Planning tersebut. Pembangunan sistem ini dilakukan sesuai dengan perancangan yang telah dibuat. Alur implementasi menggunakan UML (Unified Modeling Language).

Adapun tahapan-tahapan penelitian tertera pada Gbr.2 sebagai berikut:

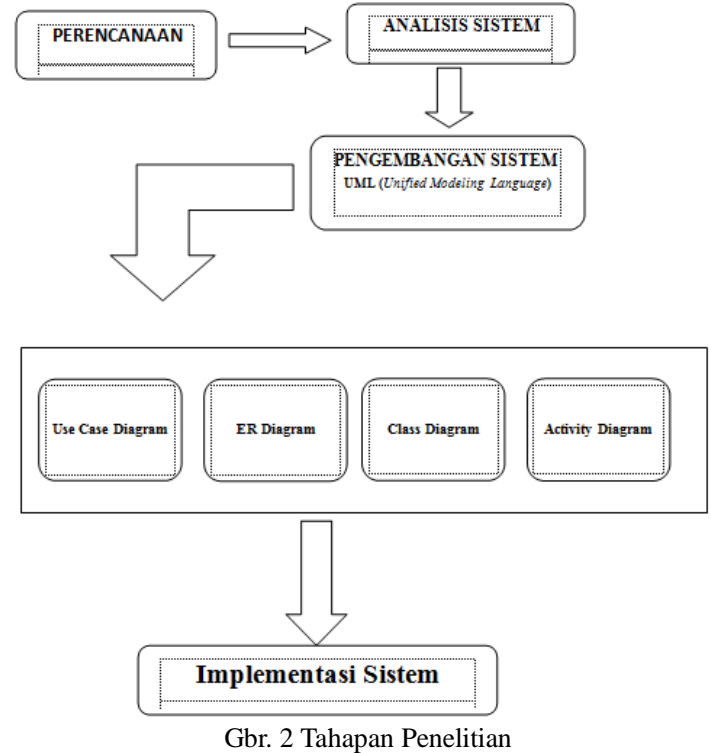

Pada Proses implementasi perancangan menggunakan terdapat bahan dan alat yang digunakan dalam penelitian tersebut, sebagai berikut:

1) Bahan

- framework CI (Codeigniter) versi 3.1.6 dengan bahasa pemrograman PHP [13].

- bootstrap dan css pada tampilannya dan menggunakan editor berupa Sublime.

- $\quad$ phpMyAdmin sebagai database MySQL.

2) Alat

- Sistem operasi: Windows 7 Ultimate 32-bit

- Prosesor:Intel(R) Core(TM) i3-7200U CPU @ $2.50 \mathrm{GHz}$ (4 CPUs), 2.7GHz Intel(R) Core(TM) i34720HQ CPU @ 2.60GHz (8 CPUs), 2.6GHz

\section{E. Testing}

Pengujian dilakukan dengan menggunakan teknik blackbox testing, dilakukan untuk mengecek sudah sesuai dengan fungsi atau belum serta ada error atau tidak. Black Box pengujian adalah metode pengujian perangkat lunak yang menguji fungsionalitas aplikasi yang bertentangan dengan struktur internal atau kerja (lihat pengujian white-box). Pengetahuan khusus dari kode aplikasi / struktur internal dan pengetahuan pemrograman pada umumnya tidak diperlukan. Uji kasus dibangun disekitar spesifikasi dan persyaratan, yakni, aplikasi apa yang seharusnya dilakukan. Menggunakan deskripsi eksternal perangkat lunak, termasuk spesifikasi, persyaratan, dan desain untuk menurunkan uji kasus. Tes ini dapat menjadi fungsional atau non-fungsional, meskipun biasanya fungsional. Perancang uji memilih input yang valid dan tidak valid dan menentukan output yang benar. Tidak ada pengetahuan tentang struktur internal benda uji itu. 
Metode uji dapat diterapkan pada semua tingkat pengujian perangkat lunak: unit, integrasi, fungsional, sistem dan penerimaan. Ini biasanya terdiri dari kebanyakan jika tidak semua pengujian pada tingkat yang lebih tinggi, tetapi juga bisa mendominasi unit testing juga. Pengujian pada Black Box berusaha menemukan kesalahan seperti:

- Fungsi-fungsi yang tidak benar atau hilang

- Kesalahan interface

- Kesalahan dalam struktur data atau akses database eksternal

- Kesalahan kinerja

- Inisialisasi dan kesalahan terminasi

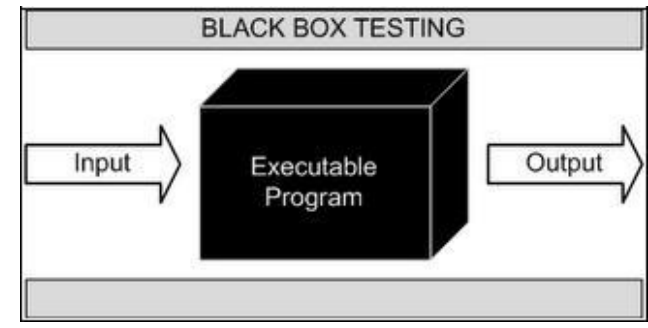

Gbr. 3 Konsep Black Box

Pada penerapan Black Box Testing pada sistem informasi advice planning di Kabupaten Probolinggo didesain untuk menjawab pertanyaan-pertanyaan sebagai berikut:

- Bagaimana fungsi-fungsi yang diuji agar dapat dinyataan valid/tidak boleh kosong pada input tertentu?

- Batasan input seperti apa yang akan menghasilkan kasusu uji yang baik?

- Bagaimana inputan yang masuk dapat tersimpan, edit dan terhapus dengan baik?

- Bagaimana jika sistem tersebut diterapkan pada bermacam-macam web Browser?

- Berapa rasio data dan jumlah data yang dapat ditoleransi oleh sistem?

- Efek apa yang akan nampak jika terdapat kombinasi data ditangani spesifik pada operasi sistem.

Hasil dari Black Box Testing memiliki banyak kesesuain yang positif dari tanya-jawab tersebut, akan tetapi kegagalan dari penggunaan web browser yang belum di-update seperti internet explore, karena mungkin belum comfortable dengan update teknologi sekarang. Dan uji coba yang lainnya berjalan sesuai dengan target peneliti.

\section{HASIL DAN PEMBAHASAN}

Advice Planning (Keterangan Rencana Kabupaten/ Kota) merupakan salah satu dokumen yang harus dilengkapi dalam rangka mengajukan Izin Membangun Bangunan (IMB). Menurut UU No. 26 Tahun 2007 tentang Penataan Ruang, menyebutkan diantaranya adalah penyelenggaraan penataan ruang yang transparan, effektif dan partisipatif agar terwujud ruang yang aman, nyaman, produktif dan berkelanjutan.

Selain fitur Advice Planning, dalam sistem juga menyediakan fitur untuk melihat Peta Kewilayahan dan Perencanaan Lahan. Izin Mendirikan Bangunan (IMB) adalah perizinan yang diberikan oleh Kepala Daerah kepada pemilik bangunan untuk membangun baru, mengubah, memperluas, mengurangi, dan/atau merawat bangunan sesuai dengan persyaratan administratif dan persyaratan teknis yang berlaku. IMB diatur dalam Undang-Undang nomor 28 Tahun 2002 tentang Bangunan Gedung, dimana Undang-undang tersebut menyatakan bahwa untuk mendirikan bangunan gedung di Indonesia diwajibkan untuk memiliki Izin Mendirikan Bangunan.

Oleh karena hal tersebut perancangan Sistem Informasi berbasis Web ini dilakukan guna meningkatkan kualitas pelayanan publik, memberikan informasi yang dibutuhkan masyarakat dalam hal perijinan dan konsultasi tata letak bangunan, serta memenuhi permintaan masyarakat dalam melakukan pengajuan perijinan serta konsultasi desain dan tata letak bangunan sesuai dengan Rencana Tata Ruang dan Wilayah di dalam suatu Pemerintah Daerah khususnya untuk Kabupaten Probolinggo.

Berdasarkan analisis permasalahan dan data yang diperoleh, berikut adalah paparan mengenai kebutuhan pengguna yang berjalan di dalam sistem. Kebutuhan tersebut antara lain User Identification, Functional Requirement, dan Non-Functional Requirement.

User Identification merupakan identifikasi pengguna (aktor) ya sistem functional requirement adalah tombol cepat dalam pemanggilan menu. Sistem Advice Planing Online ini, juga terdapat kebutuhan non fungsional (nonfunctional requirement).

Adapun beberapa sistem yang digunakan menggunakan UML (Unified Model Language), seperti dibawah pemaparannya [14], pada proses UML ini menggunakan perancangan seperti Use case diagram, sequence diagram, State Chart Diagram dan Class diagram [15].

\section{A. Perancangan dan Desain Sistem \\ 1) Use Case Diagram}

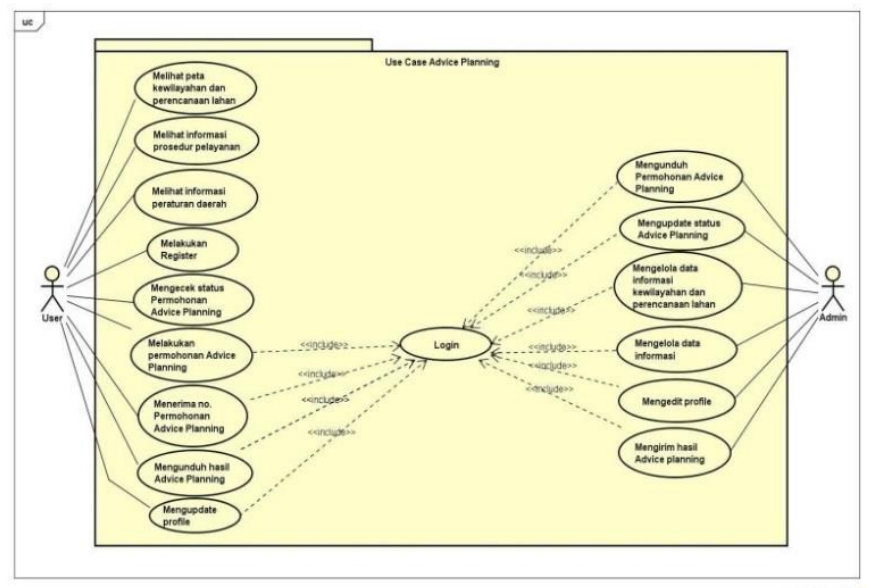

Gbr. 4 Use Case Diagram Advice Planning

Use Case Diagram Advice Planning pada Gbr.4 menunjukan proses dari user dan admin. Secara deskripsi memberikan pemaparan apa saja yang dilakukan baik user ataupun admin pada sistem advice Planning. Setelah beberapa tindakan yang dilakukan oleh user dan admin berikutnya adalah pengaturan dari tabel atau desain database yang terangkum dalam ER Diaragram, sebagai berikut: 
2) ER Diagram

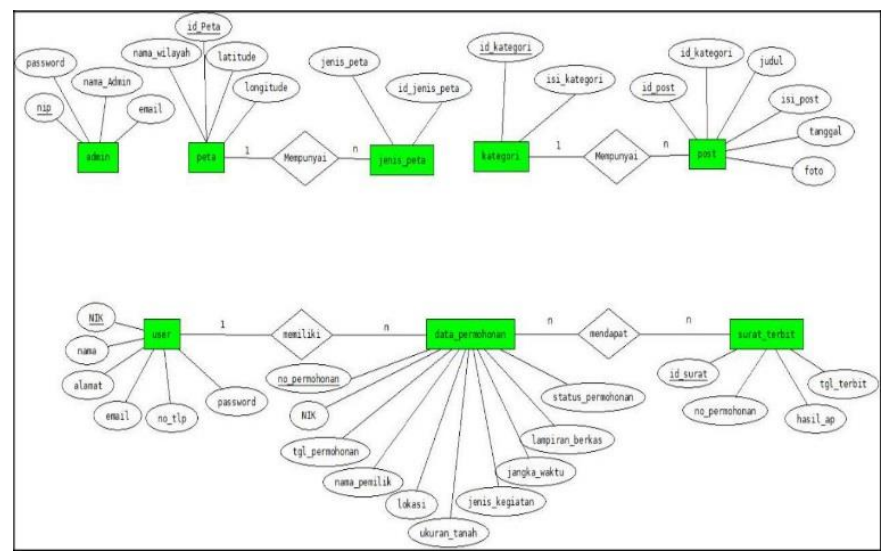

Gbr. 5 ER Diagram Advice Planning

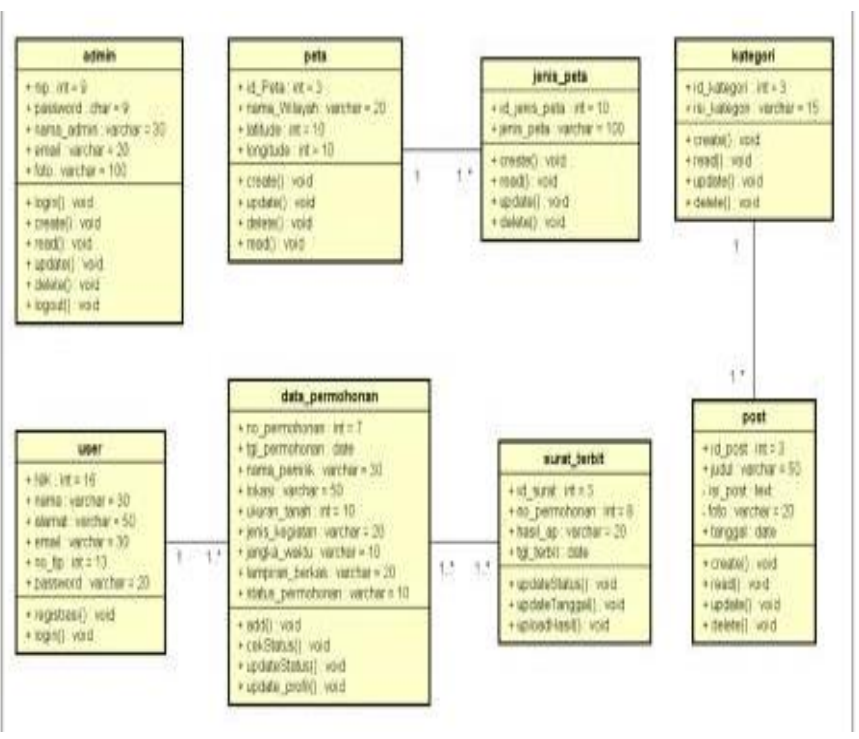

Gbr. 6 Class Diagram Advice Planning

Pada Gbr.5 ER Diagram [3] Advice Planinng menjelaskan tentang desain database, atribut atau field pada tabel dan proses one to many, one to one atau many to many dari tabel databasenya. Jumlah tabel di atas adalah 8 (delapan), nama tabelnya adalah admin, peta, jenis_peta, Kategori, post, user, data_permohonan dan surat terbit. Dari tabel-tabel yang ada dikelola menjadi sistem komputerisasi secara online. Tahapan berikutmya adalah pembuatan Class Diagram sebagai pengaturan sistem alur proses sistem seperti pada Gbr.6.

\section{3) Class Diagram}

Class Diagaram adalah salah satu sistem model pada UML, yang berfungsi mengatur proses-proses yang digunakan dalam membangun suatu sistem. Dengan adanya Class Diagram memberikan kemudahan dalam menentukan proses query pada database yang dibutuhkan [16].

\section{4) Activity Diagram}

Activity Diagram adalah gambaran alur dari setiap aktivitas-aktivitas di dalam sistem yang berjalan [15]. Data yang dibuat pada aktivitas tersebut adalah proses alur pengajuan, pada Gbr.7.

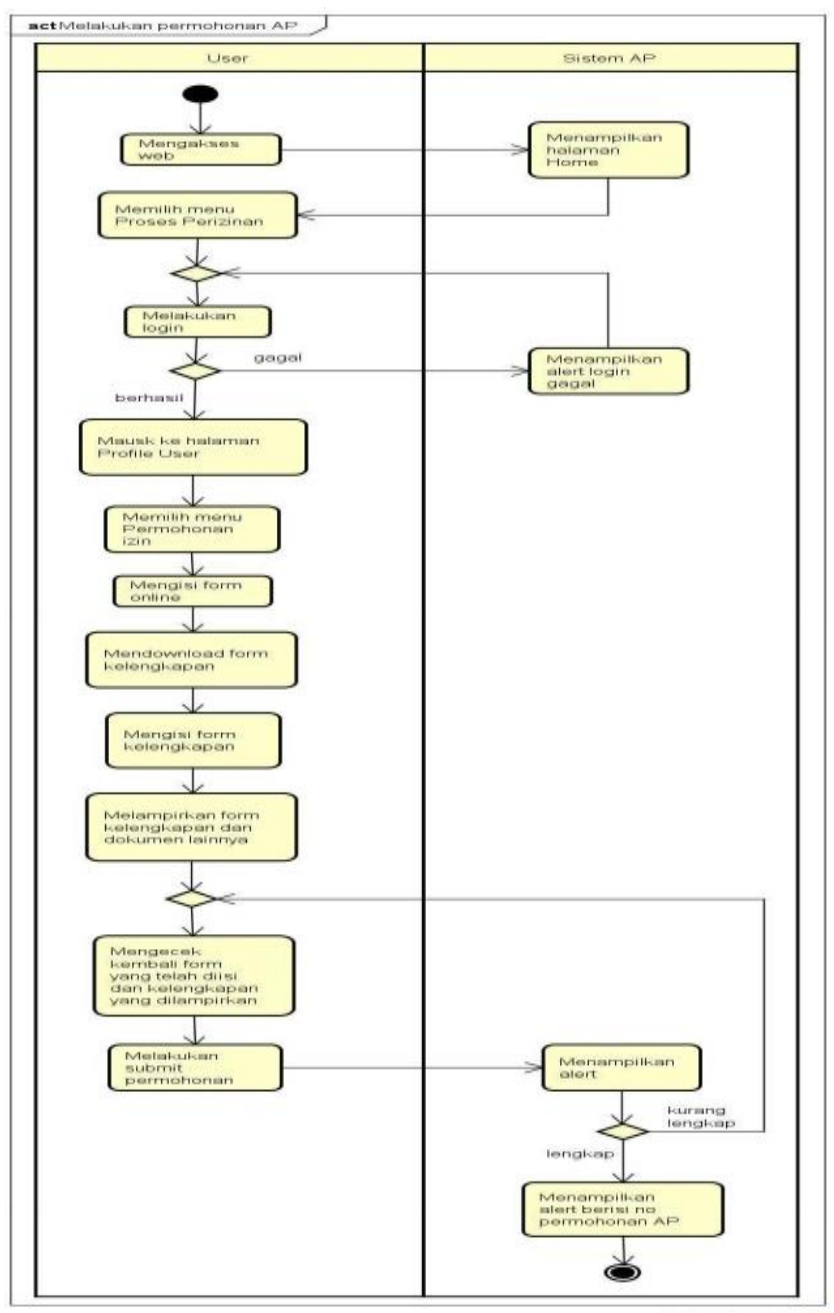

Gbr. 7 Activity Diagram melakukan permohonan Advice Planning

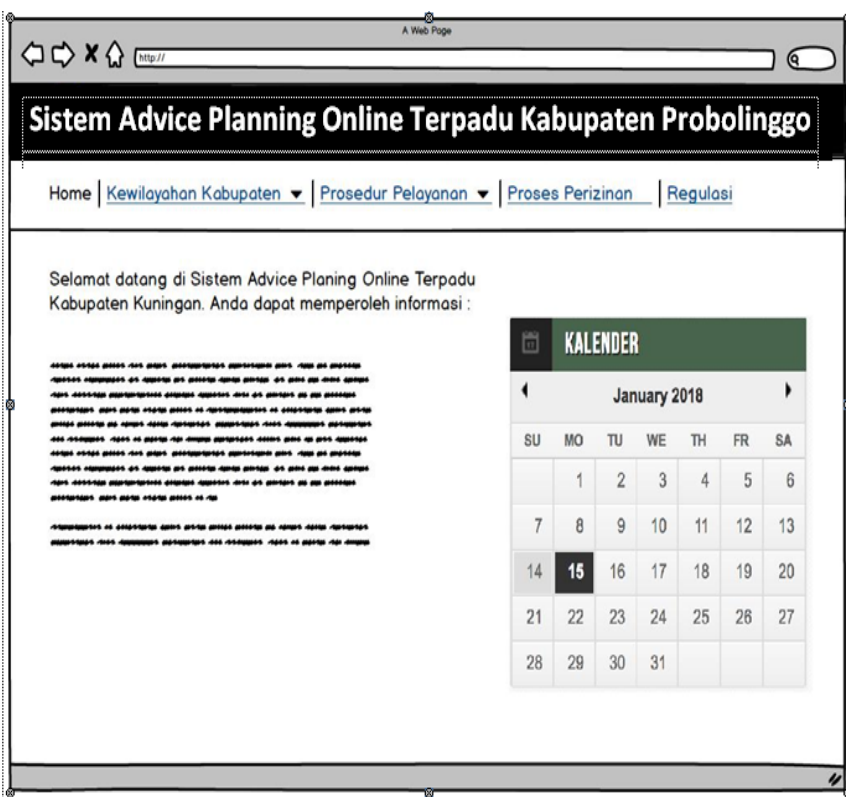

Gbr. 8 Tampilan Awal Aplikasi Advice Planning 


\section{B. Implentasi Advice Planning}

Adapun beberapa hasil dari aplikasi Advice Planing, sebagai berikut:

\section{1) Tampilan Interface Awal}

Gbr. 8 menunjukan Dasbord pada sistem advice Planning online terpadu pada Kabutapaten Probolinggo.

\section{2) Interface Proses Pengajuan}

Proses pengajuan online adalah salah satu inovasi menjadi dari proses manual ke proses komputerisasi, tentunya proses tersebut khusus user pemohon, sehingga memberikan kemudahan dalam pengajuan advice Planning tanpa adanya batasan waktu dan tempat. Dengan adanya sistem tersebut akan memberikan kemudahan kepada masyarakat dalam mengajukan advice planning ke pemerintah Kabupaten Probolinggo tanpa terhalang waktu dan tempat. Alur yang lebih detail untuk masyarakat terpadat gambar 7 aktifitas dalam melakukan permohonan dan gambar 9 pengajuan secara online advice planning.

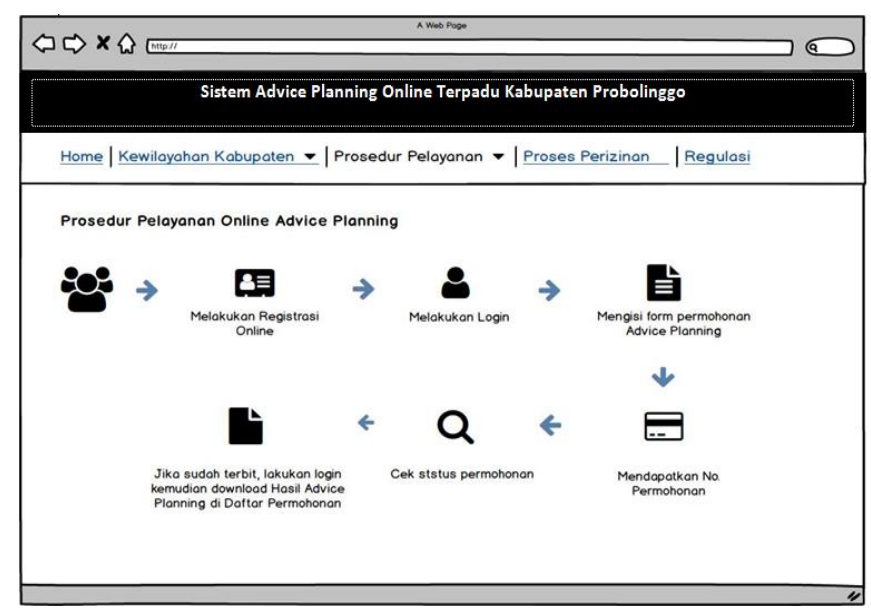

Gbr. 9 Tampilan Pengajuan online Aplikasi Advice Planning

\section{KESIMPULAN}

Adapun kesimpulan dari penelitian pada sistem Advice Planing Online dengan Framework Codeigniter berbasis web Bootstrap adalah sistem Advice Planning merupakan layanan jasa sebagai salah satu solusi e-goverment. Pelayanan Advice Planning bertujuan untuk mengoptimalisasi pelayanan publik dalam sektor perijinan dan optimalisasi manajemen instansi. Pelayanan perijinan berwujud konsultasi desain dan letak bangunan yang sesuai dengan rencana tata ruang dan wilayah di dalam suatu pemerintah daerah khusus Kabupaten Probolinggo. Proses perizinan yang harus dipenuhi oleh calon investor baik secara individu atau atas nama perusahaan serta infrastruktur pendukung yang ada di sekitar lokasi investasi. Sistem memberikan kemudahan bagi pengajun dalam mengajukan Advice Planning tanpa tergantu tempat dan waktu

\section{UCAPAN TERIMA KASIH}

Ucapan terimakasih ini disampaikan kepada Rektor UNUJA (Univeritas Nurul Jadid), Dekan Fakultas Tekini UNUJA, Kap. Prodi Fakultas Informatika UNUJA dan rekan seperjuangan, Dosen Informatika Univeritas Nurul Jadid yang telah memberikan dukungan Moril dan Moral sehingga penelitian ini terselesaikan dengan baik.

\section{DAFTAR PUSTAKA}

[1] L, Jimmy Gaol, Sistem Informasi Manajemen Pemahaman dan Aplikasi. Jakarta: Penerbit PT Grasindo, 2005.

[2] Suyatno, "PENGGUNAAN DAN PENERAPAN TEKNOLOGI INFORMASI SEBAGA SISTEM PENDUKUNG KEPUTUSAN (SPK) (Studi Kasus di Lembaga Pemerintahan Daerah Kabupaten Jepara) ," Jurnal Pengembangan IT (JPIT), vol. 1, p. 10, Ja 2016.

[3] Muhamad \& Oktafianto Muslihudin, Analisis dan Perancangan Sistem Informasi Menggunakan Model Terstruktur dan UML. Yogyakarta. Yogyakarta: Andi Offset, 2016.

[4] Muhamad Arifudin. (2014) https://www.scribd.com/. [Online]. https://www.scribd.com/doc/214820799/Advice-Planning

[5] Agus Sasmito Aribowo , Fito Nichito, Budi Santosa, "SISTEM INFORMASI GEOGRAFIS PENATAAN RUANG DAN," TELEMATIKA, vol. 10, no. 2, pp. 153 - 160, Januari 2014.

[6] Anhar, Trik Seo Security codeigniter. Jogjakarta: Lokomedia, 2018.

[7] MARECI SUSI AFRISCA SEMBIRING, "EFEKTIVITAS ADVIS PLANNING DALAM PELAYANAN IZIN ," Universitas Atma Jaya Yogyakarta, p. 17, April 2015.

[8] Ade Irama Suryani, "Implementasi Penerbitan Ijin ," Undip Semarang, 2008.

[9] Muhammad Ridha Albaar and Achmad Rosdiani, "Analisis Sistem Informasi Pelayanan Izin Mendirikan Bangunan Menggunakan Pendekatan Framework ITPOSMO (Studi Kasus Dinas Tata Kota dan Pertamanan Kota Ternate)," Seminar Nasional Teknologi Informasi dan Multimedia, p. 6, Januari 2013.

[10] Richard Heeks, Most eGoverment-for-Deveploment Projects Fail : How Can Rsisks Be Reduced?.: Instutite for Development Policy and Management, 2003.

[11] Antony Susanto, Perancangan Ujian Online pada STMIK GI MDP Berbasis Web., 2008.

[12] Sri Mulyani, Sistem Informasi Menejemen Rumah Sakit : Analisis dan Perancangan. Bandung: Abdsi Sistematika, 2016.

[13] Vidiandry \& Supono Putratama, Pemrograman Web dengan menggunakan Framework Codeigniter. Yogyakarta: Deepublish, 2016.

[14] Evi \& Gede Suardika Triandini, Step by Step Design Proyek Menggunakan UML. Yogyakarta: Andi Offset, 2012.

[15] M Teguh Prihandoyo, "Unified Modeling Language (UML) Model Untuk, " Jurnal Pengembangan IT (JPIT), vol. 3, p. 4, Januari 2018.

[16] D. P., Dennis, A., \& Wixom, B. H. Tegarden, Systems Analysis and Design with UML.: John Wiley \& Sons inc, 2012. 